\title{
Simulating the Law: Experiential 'Teachniques' in the Modern Law Curricula
}

The concept of arguing aspects of legal scenarios in order to facilitate student learning within the law curriculum originated in the vocational Inns of Court in $14^{\text {th }}$ century England (Dickerson, 2000). Nowadays, simulations of court proceedings, such as moot courts and mock trials, are widely employed as educational tools in law modules in third level institutions, both academic and vocational, around the world (Knerr et al., 2001) in order to foster advocacy and legal reasoning skills (Hernandez, 1998). However, there is a dearth of empirical research (with the exception of Lynch, 1996 and Keyes \& Whincop, 1997) on the actual benefits of such experiential learning techniques for students. The majority of literature on this topic tends to rely heavily on anecdotal evidence, provided by law lecturers on how he/she perceived that such tools benefitted his/her students (Gaubatz, 1981; Kenety, 1995; Hernandez, 1998). In order to properly evaluate whether or when such experiential learning techniques should be included in a law curriculum, a project was carried out in the School of Law and Government at Dublin City University in the academic year 2008 - 2009, in order to assess their benefits as a pedagogical tool at both undergraduate and postgraduate level. Perhaps differing from the approach to simulations which is adopted in many law courses in third level institutions, whereby there is a stand-alone 'Moot Court' module in place, the project carried out at DCU integrated the experiential learning techniques into substantive modules within the law curriculum.

The undergraduate ‘Criminal Law' class carried out a Mock Trial in relation to a murder charge. In advance of the 'trial' itself, students were provided with a basic outline of the facts and any relevant witness statements. A brief preparatory workshop 
on courtroom etiquette and evidential issues was conducted by a barrister. At 'trial' the students played all courtroom roles from witnesses and jurors to counsel and judge. This Mock Trial was linked to the assessment of this module, but was not a compulsory part thereof.

The postgraduate 'International Law and the Use of Force' class undertook an International Court of Justice simulation exercise with students representing 'States' arguing both sides of a case concerning the use of force under international law. They prepared written memoranda of legal arguments prior to the 'court hearing' and, following a preparatory workshop with a barrister, they made oral submissions to the 'court'. In this instance, the Moot Court was the basis of assessment for the module.

In order to gain empirical evidence in relation to the benefits of moot courts and mock trials in the curriculum, a questionnaire focusing on the learning experience and the learning outcomes of these techniques was distributed to the students. Student feedback suggests that the mock trial and moot court exercises were a success at both undergraduate and postgraduate levels. While some students were nervous prior to the event, the vast majority of students ultimately believed that they had honed their legal reasoning and argument skills; improved their skills of critical analysis; and, built their confidence. Students, more broadly, considered that they:

- had gained transferable skills which they would not have otherwise acquired ("It was good to be put in a formal situation where we had to defend our case. It's always good to learn strategies on how to present and sell yourself”; "This provided a unique setting for learning which is not available in other forms of assessment”); 
- had engaged with the course material more than would otherwise have been the case ("A lot can be learned from books but it is important to experience it in its proper setting”); and,

- would like to have more opportunities to participate in such real-life scenarios and simulations in their study of the law ("Hands-on learning makes learning about the law more exciting and interesting”).

Perhaps just as importantly, students generally declared that they had enjoyed the experience and in fact it had been "good fun”!

It seems clear that exercises such as moot courts and mock trials should have a prominent place in the modern law curriculum because of the benefits which accrue to students. Nonetheless, the lecturers involved in the simulations at DCU recognised, as have others before (e.g. Gaubatz, 1981; Dickerson, 2000) that undertaking such experiential learning projects is time-consuming and poses certain challenges, including, but not limited to, the design of the simulation, preparation of students and assessment design. Despite the benefits to students, these factors must also be taken into consideration when deciding the place of experiential learning techniques in the modern law curriculum.

While this empirical research study has resulted in concrete verification of the general suggestion that experiential learning techniques have many benefits for students, further empirical research on simulations in the teaching of law is still necessary. Future studies might focus on cost-benefit analyses, taking into account staff challenges and time constraints as balanced against the rewards to students, or on 
other issues, for example, whether or not prospective employers see a value in projects such as moot courts or mock trials. As Gaubatz has said "The field is only waiting to be tilled by those with the interest to tap it” (Gaubatz, 1981).

\section{References}

Dickerson, Darby ‘In Re Moot Court’ (2000) xxix Stetson Law Review 1217

Gaubatz, John T. 'Moot Court in the Modern Law School” (1981) 31 Journal of Legal Education 87

Hernandez, Michael V. 'In Defense of Moot Court: A Response to "In Praise of Moot Court - Not!"' (1998) 17 The Review of Litigation 70

Kenety, William H. 'Observations on Teaching Appellate Advocacy' (1995) 45 Journal of Legal Education 582

Keyes, Mary \& Whincop, Michael 'The Moot Reconceived: Some Theory and Evidence on Legal Skills’ (1997) 8 Legal Education Review 1

Knerr, Charles R., Sommerman, Andrew S. and Rogers, Suzy K. 'Undergraduate Appellate Simulation in American Colleges', (2001) 19 The Journal of Legal Studies Education 27

Lynch, Andrew 'Why do we Moot? Exploring the Role of Mooting in Legal Education’ (1996) 7 Legal Education Review 67 


\section{Acknowledgements}

The simulation project was funded by monies received from the Learning Innovation Unit at Dublin City University. 